\title{
Amniotic fluid embolism: literature review and an integrated concept of pathomechanism
}

\author{
Mieczysław Uszyński
}

Department of Propedeutics of Medicine, Collegium Medicum in Bydgoszcz, Nicolaus Copernicus University, Torun, Poland. Email: mieczyslaw.uszynski@.cm.umk.pl

Received 27 July 2011; revised 31 August 2011; accepted 22 September 2011.

\begin{abstract}
Literature concerning procoagulant activity of the amniotic fluid and pathomechanism of amniotic fluid embolism (AFE) was surveyed and a new concept of its pathogenesis, called the integrated concept of AFE, was presented. According to this concept, two components of the amniotic fluid are involved: 1) apoptosis-affected amniotic cells showing a special role in the initiation of disseminated intravascular coagulation (DIC) and 2) leukotrienes (formerly called slowreacting substances), inducing bronchial and pulmonary vascular smooth muscle contraction. Although each of these components initiates a different pathogenic pathway, they both lead to the formation of a mechanical barrier on blood flow through the lungs (amniotic debris + microemboli) and/or functional barrier (pulmonary vasoconstriction). An old dilemma, concerning indications for heparin therapy in AFE was recalled in the light of the new concept.
\end{abstract}

Keywords: Amniotic Fluid Embolism; Amniotic Cells; Tissue Factor; Leukotriens; Disseminated Intravascular Coagulation; Pulmonary Vasoconstriction

\section{INTRODUCTION}

Amniotic fluid embolism (AFE) is a rare but serious condition that affects, according to earlier figures, 1 - 15 cases per 100,000 births, with a case fatality rate ranging between $13 \%$ and $86 \%$, whereas according to one of the latest figures 7.7 per 100,000 births, with a case fatality rate of $21.6 \%$ (for ref. see: [1]). It is most common during labor $(70 \%)$, although it may also develop after natural delivery $(11 \%)$ and during or after Cesarean section (19\%) [2].

AFE has been diagnosed since 1941, when two American gynecologists, Steiner and Lushbaugh [3], described eight cases of sudden death of childbearing women It was only after their publication that Meyer's report of
1926 was noticed - the description also based on the pathomorphology of the lung tissue [4].

Two clinical forms of AFE can be distinguished: 1) typical, (classic) with three phases (phase 1-respiratory and circulatory disorders, phase 2 -coagulation disturbances of maternal hemostasis, phase 3-acute renal failure and acute respiratory distress syndrome (formerly: adult respiratory distress syndrome, ARDS), and 2) atypical, without the phase of respiratory-circulatory disorders, beginning with hemostasis disorders in the mother e.g. uterine hemorrhage or sometimes ARDS and renal failure.

Three theories explain the pathomechanism of respiratory-circulatory disorders and coagulation disturbances in AFE, each of which have different premises. Briefly, according to the mechanical theory, fetal squames and other morphotic and amorphotic components of the fluid act as a causative factor, blocking the pulmonary circulation; the thromboplastin theory states that the obstructtion is due to disseminated intravascular coagulation (DIC), whereas according to the leukotriene theory, it is leukotrienes that cause catastrophic pulmonary vasoconstriction.

In the last 20 years, there have appeared case reports of amniotic fluid embolism that cannot be explained by any of the known theories. This mainly refers to the cases of atypical embolism [5-8]. For instance, we cannot explain the mechanism of isolated disseminated intravascular coagulation based on the leukotriene theory.

\section{STUDY OBJECTIVE}

The objectives of the study were to: 1) assess, based on literature survey, thrombogenic potential of the amniotic fluid; 2) discuss discrepancies between the existing theories of amniotic fluid embolism; 3) present a novel concept of AFE which eliminates the discrepancies concerning the pathomechanism of this complication and takes into consideration new clinical and laboratory observations. 


\subsection{Historical Considerations Concerning the Mechanism of AFE}

a) Pioneer researchers of AFE, Steiner and Lushbaugh [3], believed that cardiopulmonary collapse was caused by disseminated pulmonary embolism of amniotic debris of fetal origin (squamous cells, lanugo hairs, mucus threads and fat droplets), and not by a biochemical mechanism (mechanical theory of AFE).

b) Many authors - at first Weiner, Reid and Roby in 1949 [9], and later also others - based their explanations on the presence of tissue factor (TF; formerly called tissue thromboplastin), a procoagulant, in the amniotic fluid. When the amniotic TF gets to the pulmonary arterioles, it induces, as they thought, intravascular coagulation. The microemboli block blood flow through the lungs and what is more, consumption coagulopathy occurs (in this way respiratory and circulatory disorders were explained from the point of view of thromboplastin theory).

c) The premises of the leukotriene concept of AFE were first described in the years 1985 and 1986 [10,11], though an overview of the theory contents was provided in 1990 [12]. The animal studies revealed that infusion of these substances resulted in severe pulmonary hypertension followed by systemic hypotension with negative inotropic effect and decreased cardiac output. It was assumed that the action observed in animals could occur in humans as well. According to this theory, metabolites of the arachidonic acid cascade-mainly leukotrienes, previously known as slow-reacting substance, but also thromboxan A2 (TXA2) and others-cause catastrophic pulmonary vasoconstriction in amniotic fluid embolism. These metabolites either pass to the lungs with the amniotic fluid or are formed in loco after the fluid gets to the pulmonary vessels.

The leukotriene concept of AFE has predominated over the previous concepts. However, the search for potent vasoconstrictors and bronchoconstrictors that could induce embolic symptoms is still continued. Currently, there are three or even four candidates: leukotrienes + endothelin-1 + bradykinin + thrombin (see below). However, whether the action of these substances on the pulmonary vessels and bronchi is synergistic still remains unknown.

d) In 1995, hypoxia in AFE was suggested to stimulate local production (in the lungs) of endothelin-1 which is a known potent vasoconstrictors and bronchoconstrictors (experimental studies) [13]. Later it was reported that amniotic squames could also be the source of endothelin-1 [14].

e) In 2005, the role of bradykinin in the pathogenesis of respiratory and circulatory disorders in AFE was discussed [15]; bradykinin was suggested to cause contrac- tion of smooth muscles of the lungs and bronchi, and to impair pulmonary microcirculation. As far as kinins are concerned, kininogenesis is a process associated with coagulation and fibrinolysis. Two factors are a common link, namely kallikrein and high-molecular kininogen (HMK). Under the effect of kallikrein, three kinins are formed from kininogen: Met-kallidin, kallidin and bradykinin. Kinins are degraded by kininases. All components of the kininopoietic system have been found in the amniotic fluid [16]. The most active of the kinin group is nanopeptide bradykinin.

f) In 2009, Zhou et al. [17] identified (described) the presence of phosphatidylserine (PS) in amniotic cells and showed its role in the process of thrombin production. The involvement of amniotic cells in the generation of thrombin is the key to the elucidation of DIC mechanism in AFE (see further).

\subsection{Formation and Composition of the Amniotic Fluid (Remarks)}

In the second half of the gestation period, amniotic fluid is mainly a product of the fetus and only to a small extent generated by fetal membranes. Fetal excretions pass directly to the fluid (primary urine, lung, oral and nasal excretion). They contain epidermal cells, fetal lanugo and sebaceous gland secretions from the fetal skin (vernix caseosa), desquamated bronchial cells, nasopharyngeal cells and urinary tract cells as well as desquamated cells of the umbilical cord and fetal membranes. In the case of fetal distress (asphyxia, intrauterine infection), meconium is excreted from the alimentary tract of the fetus to the fluid $[18,19]$.

\subsection{Procoagulants and Anticoagulants in Amniotic Fluid}

In the past, as a rule, procoagulants, anticoagulants and fibrinolytic components were searched only in the supernatant, whereas sediment was treated as a biologically inactive material. The first report on the distribution of procoagulants in the two fluid fractions, i.e. supernatant and sediment, appeared only in the last ten years. It has been found that TF is a predominant procoagulant in the supernatant, whereas other coagulation factors show only a few percent of the global procoagulant activity; TF and a few coagulation factors in an active form (IIa, VIIa and Xa) were detected in sediment [20].

The amniotic fluid does not contain fibrinogen, factors $\mathrm{V}$ and VIII, but it has all other procoagulants (coagulation factors: II, TF, VII, IX, X-XIII, prekallikrein and high molecular kininogen, HMK) and anticoagulants (tissue factor pathway inhibitor, TFPI; antithrombin, AT; protein $\mathrm{C}$ and $\mathrm{S}$; thrombomodulin, $\mathrm{TM}$ ), which were identified by activity or antigen. The levels of procoagu- 
lants and anticoagulants are very low as compared to the plasma ( $3 \%-5 \%$ of plasma value). The exception is $\mathrm{TF}$, whose level in the fluid is higher than in the plasma (for ref. see: [21]). The higher-molecular weight $(46,000)$ form of TF predominates in amniotic fluid (in tissues $40,000-46,000$ ) [20]. It is assumed that the major source of TF in amniotic fluid is the cells of desquamated epidermis of the fetus.

There is evidence for the functioning of the coagulation cascade in amniotic fluid, although its range is incomplete due to a lack of fibrinogen. However, high thrombin markers (fragments of prothrombin F1 2 and thrombin-antithrombin complexes, TAT) indicate that thrombin is generated there. Thrombin substrates in loco include protein $\mathrm{C}$ and pro-TAFI (procarboxipeptydase B); the anticoagulant called activated protein $\mathrm{C}$ (APC) and thrombin activatable fibrinolysis inhibitor (TAFI), a spectacular link between coagulation and fibrinolysis, are formed there (for ref. see: [21]).

Moreover, the fluid contains other enzymatic systems having cascade dynamics, which can generate pathogenic substances, such as leukotrienes (arachidonic acid cascade) and kinins (kallikrein-kinin cascade). Also all proteins of the fibrinolytic system and products suggesting plasmin activation are found there (for ref see: [22]).

\subsection{The Thrombogenic Role of Amniotic Cells}

The majority of amniotic cells are derived from exfoliation of squamous epithelium of the skin, from the mucous membranes of the fetus (respiratory, digestive and urinary tracts), the umbilical cord and the amnion [19]. During pregnancy, amniotic cells gradually and inevitably go to apoptosis, gaining the properties of a particular type of procoagulant (procoagulant-like activity).

The apoptotically altered amniotic cells harbor an aminophospholipid called phosphatidylserine (PS) (externalization from the inner layer of the cell membrane), which has a negative charge and thus can accumulate on the cell surface factors that become positively charged when interacting with calcium ions $\left(\mathrm{Ca}^{2+}\right)$, i.e. the factors necessary to the formation of thrombin. The proximity and the surface (the platform) create conditions for the coagulation factors to interact. Thus, the interaction of TF with VIIa yields a TF/VIIa complex at first, and then a triple tenase complex of TF/VIIa/X, which in the presence of calcium ions transforms the proenzyme, prothrombin, into the active serine enzyme, thrombin. Although the action of amniotic thrombin is restricted in normal conditions to the amniotic fluid, in AFE amniotic cells act as ready foci of DIC.

The role of amniotic cells in the generation of thrombin is a discovery which is the key to elucidate the mechanism of DIC in amniotic fluid embolism [17]. Al- ready in 1970, Slunsky [23], a Czech/Austrian author, in his book on AFE noticed that amniotic cells were frequently found inside microthrombi. We now consider it to be the effect of thrombin formed on amniotic cells and transforming fibrinogen into fibrin in its closest vicinity.

Here, a cell-based model of hemostasis proposed by Hoffman and Monroe [24] in 2001 should be recalled. According to this model, the surface of fibroblasts and platelets constitutes a platform for the process of thrombin generation-first thrombin is produced in ignition amounts (initiation of coagulation), followed by subsequent phases (amplification and propagation), in which thrombin is generated in the amount able to produce a hemostatic plug. The surface of amniotic cells can thus have a similar role in the process of initiation of coagulation as the surface of fibroblasts and blood platelets. Amniotic cells seem to compensate for the lack of blood platelets in amniotic fluid.

\subsection{The Phenomenon of Pathogenic Potential of Amniotic Fluid}

Since the turn of the 1940 s/50s there has been a dispute attempting to elucidate whether the amount of TF in amniotic fluid embolism can elevate significantly TF concentration in the mother's blood and whether this amount can induce DIC. Researchers have varied in their opinions in this field.

In 1957 Schneider [25] wrote: "Plausible as this at first seems, proof of significant release of thromboplastin is still lacking". In 1972 Phillips and Davidson [26] concluded their research with the following: "The amount of procoagulant ... is probably insufficient to cause signifycant intravascular coagulation...”. A spectacular calculation by Mac Millan of 1968 [27] stated that the pathogenic amount of TF could be found in 7 liters of the fluid, whereas the volume of a genuine embolus was estimated at $10 \mathrm{ml}-100 \mathrm{ml}$. Meta-analysis of my own study of 2003 [28] showed that TF contained in $100 \mathrm{ml}$ supernatant could cause only a statistically insignificant increase in TF concentration in maternal blood (not exceeding standard deviation).

Despite these reservations, there can be a positive answer to the question concerning the pathogenicity of amniotic TF. The following hypothesis can be proposed: There are two TF fractions in amniotic fluid: 1) free fraction found in the supernatant and 2) TF-cell bearing (harboring) fraction, bound to the apoptosis-affected amniotic cells. Only the TF fraction found on the surface of amniotic cells can be ascribed the role of the initiator of coagulation. These cells - after reaching pulmonary arteries (amniotic embolism) - immediately become the foci of fibrinogen transformation into fibrin (coagulation), since they already have thrombin, an active serine 
enzyme, on their surface. On the other hand, the fraction of "free TF", i.e. TF found in the supernatant, does not play a pathogenic role in amniotic fluid embolism.

Thus, the phenomenon of the thrombogenic potential of amniotic fluid can be explained by integrated action of three factors: 1) PS found on amniotic cells; 2) TF and a few other coagulation factors that accumulate on amniotic cells and form thrombin, and 3) the very amniotic cells which make a platform for thrombin generation.

\section{NEW CLINICAL OBSERVATIONS}

During the last 20 years some new, spectacular and effective diagnostic and therapeutic methods have been described, which inspires revision of the common views. This refers to e.g. the case of embolism after Cesarean section reported by Esposito et al. in 1991 [29] and durg Cesarean section described by Stanten et al. in 2003 [30]. In both cases, circulation arrest occurred and since standard resuscitation procedure was ineffective, after full heparinisation, cardiopulmonary bypass was instituted with a successful result. In the former case [29], massive embolisation to the lung (pulmonary perfusion scan) and embolus in the pulmonary artery with high concentration of fetal squames (thromboembolectomy) were detected, in the latter [30] - although the lumen of the pulmonary arteries was free, transesophageal echocardiogram showed catastrophic pulmonary vasoconstriction. In both cases severe consumption coagulopathy was observed.

These descriptions can be interpreted in the following way: 1) disseminated intravascular coagulation (DIC) takes place not only in pulmonary arterioles, but can also reach the bifurcations and even the trunk of the pulmonary artery, with fetal squamous cells and fibrin forming "primary + secondary" embolic material (case 1);2) two pathogenic routes may exist alongside (catastrophic DIC and catastrophic pulmonary vasoconstriction), and therefore both routes should be considered during therapy (case 2); 3) full heparanisation was performed in cardiopulmonary bypass procedure, which undoubtedly facilitated the maintenance and recovery of pulmonary vascular patency; 4) The process of DIC was already present at the very beginning of the complication and if so, only a targeted and immediate treatment could reduce this process (pathogenetic treatment).

\subsection{An Integrated Concept of Amniotic Fluid Embolism}

In the integrated concept of amniotic fluid embolism (Figure 1), two amniotic fluid components, i.e. the apoptosis-affected amniotic cells and leukotrienes play a role.
AMNIOTIC FLUID EMBOLISM

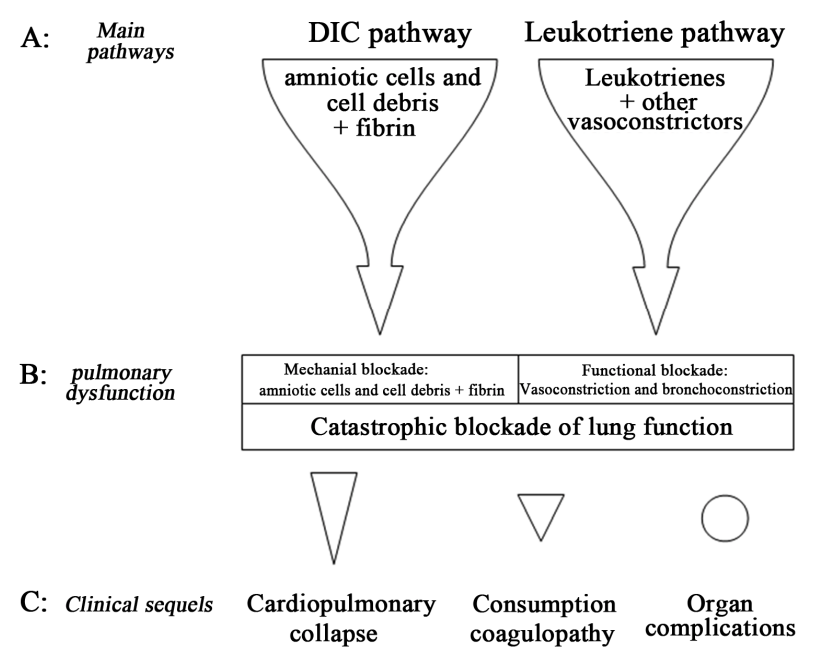

Figure 1. The mechanism of respiratory and circulatory disorders in amniotic fluid embolism: two pathogenic pathways (A) leading to catastrophic blockade of lung function (B), and clinical sequels (C).

Each of these components induces different pathogenic pathway (chain) in pulmonary vessels: 1) the apoptosis-affected cells become foci of thrombin, which leads to DIC (DIC pathway); 2) leukotrienes and other metabolites of arachidonic acid cascade, and possibly coexisting with them vasoactive substances, e.g. amniotic endothelins, kinins and shock neurotransmitters, as well as thrombin generated in the coagulation foci cause catastrophic pulmonary vasoconstriction together with a chain of sequels due to anoxia (the leukotriene pathway).

The obstruction of blood flow through the lungs is a direct cause of cardio - pulmonary collapse. The blockade occurs due to the following: 1) blood flow through the lungs is hindered or blocked by amniotic cells and amniotic debris found in pulmonary arteriolar circulation (mechanical action per se); moreover, the blockade is enhanced by secondary embolic material produced in the process of DIC (fibrin accumulating around amniotic cells); 2) pulmonary vasoconstriction caused by leukotrienes and/or other substances. Both types of disorders have the same "onset time".

\subsection{Clinical Remark}

In the light of the integrated concept of amniotic fluid embolism, an old dilemma, i.e. indication for heparin therapy in amniotic embolism, should be recalled. The use of heparin or alternative medications (streptokinase, recombinant tissue plasminogen activator, trasylol) should be discussed and decided by appropriate scientific societies. "Full heparinization"- the management mentioned in the casuistic reports cited can be indicated as a direction to follow. Literature reports on some signals con- 
cerning controlled heparin therapy in the first phase of typical embolism (for ref. see: [31]).

\section{REFERENCES}

[1] Abenhaim, H.A., Azoulay, L., Kramer, M.S. and Leduc, L. (2008) Incidence and risk factors of amniotic fluid embolismus: A population-based study on 3 million births in the United States. American Journal of Obstetrics and Gynecology, 199, E1-E8. doi:10.1016/j.ajog.2007.11.061

[2] Clark, S.L, Hankins, G.D.V., Dudley, D.A. and Dildy, G.A. (1995) Amniotic fluid embolism: Analysis of the national registry. American Journal of Obstetrics and Gynecology, 172, 1158-1169.

doi:10.1016/0002-9378(95)91474-9

[3] Steiner, P.E. and Lushbaugh, C.C. (1941) Maternal pulmonary embolism by amniotic fluid as a cause of obstetric shock and unexpected deaths in obstetrics. Journal of the American Medical Association, 117, 1245-1254.

[4] Meyer, J.R. (1992) Embolia pulmonary amnio caseosa. Clinics in Chest Medicine, 13, 657-665.

[5] McDougall, R.J. and Duke, G.J. (1995) Amniotic fluid embolism syndrome: Case report and review. Anaesthesia and Intensive Care, 23, 735-740.

[6] Bastien, J.L., Graves, J.R. and Bailey, S. (1998) Atypical presentation of amniotic fluid embolism. Anesthesia and Analgesia, 87, 124-126. doi:10.1097/00000539-199807000-00027

[7] Fletcher, S.J. and Parr, M.J.A. (2000) Amniotic fluid embolism: A case report and review. Resuscitation, 43 , 141-146. doi:10.1016/S0300-9572(99)00140-9

[8] Awad, I.T. and Shorten, G.D. (2001) Amniotic fluid embolism and isolated coagulopathy: Atypical presentation of amniotic fluid embolism. European Journal of Anasthesiology, 18, 410-413. doi:10.1097/00003643-200106000-00011

[9] Weiner, A.E., Reid, D.E. and Roby, C.C. (1949) Hemostatic activity of amniotic fluid. Science, 110, 190. doi:10.1126/science.110.2851.190

[10] Clark, S.L. (1985) Arachidonic acid metabolites and the pathophysiology of amniotic fluid embolism. Seminars in Reproductive Endocrinology, 3, 253-257. doi:10.1055/s-2007-1022623

[11] Azegami, M. and Mori, N. (1986) Amniotic fluid embolism and leukotriens. American Journal of Obstetrics and Gynecology, 155, 1119-1124.

[12] Clark, S.L. (1990) New concept of amniotic fluid embolism: A review. Obstetrical and gynecological survey, $\mathbf{4 5}$, 360-368. doi:10.1097/00006254-199006000-00003

[13] el-Maradny, E., Kanayama, N., Halim, A., Maehara, K. and Taro, T. (1995) Endothelin has a role in the early pathogenesis of amniotic fluid embolism. Gynecologic and Obstetric Investigation, 40, 14-18. doi:10.1159/000292294

[14] Khong, T. (1998) Expression of endothelin-1 in amniotic fluid embolism and possible pathophysiological mechanism. British Journal of Obstetrics and Gynaecology, 105, 802-804. doi:10.1111/j.1471-0528.1998.tb10214.X

[15] Robillard, J., Gauvin, F., Molinaro, G., Leduc, L., Adam, A. and Rivard, G.E. (2005) The syndrome of amniotic fluid embolism: A potential contribution of bradykinin. American Journal of Obstetrics and Gynecology, 193, 1508-1512. doi:10.1016/j.ajog.2005.03.022

[16] Mutoh, S., The, A., Sato, M., Aoki, N., Ohno, Y. and Itoh, N. (1989) Studies on coagulation-fibrinolysis and Kallikrein-kinin systems and kininase activity and kininase II quantity in amniotic fluid. Advances in Experimental Medicine and Biology, 247, B559-B567.

[17] Zhou, J., Liu, S., Ma, M., Hou, J., Yu, H., Lu, Ch., Gilbert, G. and Jialan, S. (2009) Procoagulant activity and phosphatidylserine of amniotic fluid cells. Thrombosis and Haemostasis, 101, 845-851.

[18] Brace, R.A. (1999) Physiology of amniotic fluid volume regulation. In: Amniotic fluid. Rao, K.A. and Ross, M.G., Eds., Prism Books Pvt Ltd., Bangalore, S110-S132.

[19] Tyden, O., Bergström, S. and Nilsson, B.A. (1980) Origin of amniotic fluid cells in mid-trimester pregnancies. British Journal of Obstetrics and Gynaecology, 88, 278286.

[20] Lockwood, C.J., Bach, R., Guha, A., Zhou, X., Miller, W.A. and Nemerson, Y. (1991) Amniotic fluid contains tissue factor, a potent initiator of coagulation. American Journal of Obstetrics and Gynecology, 165, 1335-1341.

[21] Uszyński, M. and Uszyński, W. (2011) Coagulation and fibrinolysis in amniotic fluid: Physiology and observations on amniotic fluid embolism, preterm fetal membrane rupture, and pre-eclampsia. American Journal of Obstetrics and Gynecology, 37, 165-174.

[22] Uszyński, M. (1999) Fibrinolytic system in amniotic fluid and foetal membranes. In: Amniotic fluid. Rao, A. and Ross, M.G. (red.) Prism Books Pvt Ltd. Bangalore, 163-175.

[23] Slunsky, R. (1971) Klinik der Fruchtwasserembolie. Karger, Basel.

[24] Hoffman, M. and Monroe III, D.M. (2001) A cell-based model of hemostasis. Thrombosis and Haemostasis, 85, 958-965.

[25] Schneider, ChL. (1957) Fibrination and defibrination. In: Physiologie und pathologie der blutgerinnung in der gestationsperiode. Schattauer-Verlag, Stuttgart, 15-17.

[26] Phillips, L.L. and Davidson, E.C. (1972) Procoagulant properties of amniotic fluid. American Journal of Obstetrics and Gynecology, 113, 911-919.

[27] MacMillan, D. (1968) Experimental amniotic fluid infusion. Journal of obstetrics and gynaecology of the British Commonwealth, 75, 849-852. doi:10.1111/j.1471-0528.1968.tb01604.x

[28] Uszyński, M., Żekanowska, E., Uszyński, W. and Kuczyński, J. (2001) Tissue factor (TF) and tissue factor pathway inhibitor (TFPI) in amniotic fluid and blood plasma: Implications for the mechanism of amniotic fluid embolism. European Journal of Obstetrics and Gynecology and Reproductive Biology, 95, 163-166. doi:10.1016/S0301-2115(00)00448-6

[29] Esposito, R.A., Grossi, E.A., Coppa, G., Gianola, G., Ferri, D.P., Angelides, E.M. and Andriakos, P. (1990) Succesful treatment of shock caused by amniotic fluid embolism with cardiopulmonary bypass and pulmonary artery thromboembolectomy. American Journal of Obstetrics and Gynecology, 163, 572-574.

[30] Stanten, R.D., Iverson, I.G., Daugharty, T.M., Lovett, S.M., Terrt, C. and Blumenstock, E. (2003) Amniotic flu- 
id embolism causing catastrophic pulmonary vasoconstriction: Diagnosis by echocardiogram and treatment by cardiopulmonary bypass. Obstetrics Gynecology, 102, 496-498. doi:10.1016/S0029-7844(03)00161-3
[31] Uszyński, M. (2009) Amniotic fluid embolism: The complication of known pathomechanism but without pathogenetic therapy? Thrombosis and Haemostasis, 101, 795796. 